\title{
Migration of dental implants in the maxillary sinus - a putative risk of sinus aspergilossis
}

\author{
Migrarea implanturilor dentare în sinusurile maxilare \\ - un posibil risc de aspergiloză sinuzală
}

\author{
Alexandru Andrei Iliescu', Paula Perlea ${ }^{2}$, Anca Nicoleta Temelcea ${ }^{3}$ \\ ${ }^{1}$ Facultatea de Medicină Dentară, Universitatea de Medicină şi Farmacie, Craiova, România \\ 2Facultatea de Medicină Dentară, Universitatea de Medicină şi Farmacie "Carol Davila“, \\ Bucureşti, România \\ ${ }^{3}$ Disciplina de Tehnică Dentară, Facultatea de Moaşe şi Asistenţă Medicală, \\ Universitatea de Medicină şi Farmacie „Carol Davila“, Bucureşti, România
}

\begin{abstract}
Sometimes the maxillary endosseous implants may migrate into the maxillary sinus, a quarter of them being recorded in maxillary sinus bone grafts. Less frequent it occurs after the occlusal loading or during the prosthetic abutment insertion. The displacement and retention of a dental implant in maxillary sinus causes a chronic sinusitis. One of such infection might be aspergillosis. Clinically the aspergillosis of maxillary sinus may be non-invasive, invasive or allergic. The treatment of non-invasive aspergillosis in immunocompetent individuals consists in surgical removal of infected fungal mass without a systemic antifungal medication. The invasive aspergillosis which is affecting immunocompromised persons has to be treated both by surgical and long-term systemic antifungal therapy. In allergic form the surgical removal of nasal polyp and recreation of the patency of the maxillary ostium are recommended.
\end{abstract}

Keywords: maxillary sinus, implant migration, infectious complications, aspergillosis

\section{REZUMAT}

Implanturile endoosoase inserate la maxilarul superior pot migra uneori în cavităţile sinuzale, un sfert dintre cazuri înregistrându-se după liftingul sinuzal. Mai rar, accidentul are loc după încărcarea ocluzală protetică, iar uneori s-a descris chiar şi la inserarea bontului implantar. Pătrunderea şi retenţia unui implant dentar în sinusul maxilar generează o sinuzită cronică. Printre complicaţiile infecţioase se numără şi aspergiloza. Clinic, aspergiloza sinuzală se poate manifesta prin forme neinvazive, invazive sau alergice. Tratamentul aspergilozei neinvazive la persoanele imunocompetente presupune exereza chirurgicală a masei tisulare infectate fără o terapie sistemică antimicotică. Aspergiloza invazivă, care afectează persoane imunocom-promise, trebuie abordată printr-o intervenţie chirurgicală asociată cu terapia antifungică generală de lungă durată. În forma alergică de aspergiloză sinuzală, se recomandă excizia polipului nazal şi repermeabilizarea ostiumului meatal obstruat.

Cuvinte cheie: sinus maxilar, migrare implant, complicaţii infecţioase, aspergiloză

\section{INTRODUCERE}

O dată cu introducerea în implantologie a implantelor osteointegrate, care se bucură de o rată înaltă de supraviețuire, terapia implanto-protetică a edentațiilor a căpătat o largă răspândire (1).
Succesele clinice ale ultimelor patru decenii nu trebuie să estompeze şi unele riscuri (2). Deşi rare, în tratamentele implanto-protetice sunt descrise şi complicații ale timpului operator chirurgical, caracterizate prin migrarea în sinusurile maxilare a 
implanturilor dentare inserate în zona laterală a maxilarului superior, fie intraoperator, fie postoperator, dar înainte de încărcarea protetică ocluzală $(2,3)$.

Mai rar, accidentul poate să apară după încărcarea ocluzală protetică (2-4), iar uneori chiar şi la inserarea bontului implantar (5). Din punct de vedere protetic, prin migrarea implantului dentar se pierde un stâlp de punte care va perturba rapoartele funcționale masticatorii cu antagoniştii, ducând la o supraîncărcare ocluzală a implanturilor restante (5).

De regulă, cauza principală a migrării sinuzale a implanturilor este de natură anatomică, depinzând mai puțin de tehnica chirurgicală, întrucât înălțimea şi lățimea crestei osoase alveolare edentate sunt mult reduse comparativ cu dimensiunea implantului necesară unei bune stabilități primare (5). De asemenea, o eventuală perforație a membranei schneideriene în cursul procedurii de grefare poate fi soluționată prin acoperirea cu o membrană bioresorbabilă (6).

Un element favorizant al migrării sinuzale a implanturilor dentare îl constituie osul alveolar la maxilar de slabă calitate, os de tip IV, având corticala foarte subțire şi spongioasa de densitate redusă (2). La vechii edentați, un factor nefavorabil adițional indus de rezorbția osoasă este şi pneumatizarea sinusurilor $(2,5)$.

Chiar dacă procedeele de adiție osoasă reprezintă o soluție terapeutică eficientă de compensare a deficitului cantitativ şi calitativ al crestelor edentate laterale ale maxilarului superior atrofiat, totuşi trebuie ținut cont şi de riscurile unei grefe osoase sinuzale, precum complicațiile infecțioase, insuficienta neoformare de os, comunicările buco-sinuzale şi migrarea în sinus a implanturilor inserate în grefă (6).

Deşi, de regulă, situațiile clinice de pat implantar nefavorabil din zona maxilară laterală, consecutive resorbției osoase avansate a crestelor alveolare şi pneumatizării sinusurilor maxilare, se încearcă a se rezolva prin procedee de lifting sinuzal sau folosirea unor implanturi scurte, uneori, intervențiile chirurgicale incorect planificate şi executate favorizează migrarea implanturilor în cavitatea sinuzală şi, din nefericire, incidența lor este subestimată (7). Aplicarea procedurii de lifting sinuzal la inserarea implanturilor s-a asociat cu $25 \%$ dintre implanturile migrate în sinus (2).
Un studiu retrospectiv a constatat că migrarea implanturilor dentare în sinusul maxilar afectează, în ordine descrescătoare, zona primului molar $(58,3 \%)$, zona premolarilor $(16,6 \%)$ şi molarilor secunzi $(16,6 \%)$, pe ultimul loc fiind zona primilor premolari $(8,3 \%)$ (2). Excepțional, migrarea implanturilor inserate la maxilar poate ajunge până în celulele etmoidale, recesusul sinusului frontal (8) sau chiar sinusul sfenoidal (9).

În funcție de designul implantului, acelaşi studiu a găsit incidența maximă a migrării în sinus în cazul implanturilor cilindrice $(62,5 \%)$, urmate la distanță de cele conice $(16,6 \%)$ sau implanturile tip Tramonti (8,3\%) (2). Constatarea migrării sinuzale a implanturilor dentare s-a făcut în medie după 21,2 luni (2), proporția fiind aproximativ egală între migrarea intraoperatorie şi cea premergătoare încărcării ocluzale (2). Manifestările clinice şi imagistice de sinuzită s-au constatat la 38\% dintre impanturile migrate (2).

Dacă nu se intervine chirurgical într-o perioadă scurtă de timp, implantul dentar migrat în sinus declanşează treptat o inflamație cronică cu îngroşarea mucoasei schneideriene şi opacifierea cavității sinuzale pe imaginile radiografice. Clinic, există o jenă dureroasă permanentă în zona posterioară a maxilarului superior afectat şi sensibilitate la palpare.

Sinuzita cronică generată de pătrunderea şi retenţia unui implant dentar în sinusul maxilar are drept consecință blocarea clearence-ul mucociliar şi micşorarea ostiumul meatal prin îngroșarea mucoasei (5).

Implanturile recuperate chirurgical la peste 5 ani de la migrarea în sinus sunt învelite de țesut fibros evoluând spre degenerescență hialină. Se produc, de asemenea, fenomene de degenerescență chistică şi tromboză pe fond de infiltrat inflamator redus (10).

Pentru evitarea complicațiilor infecțioase inerente, atitudinea clinică corectă în fața unui asemenea eveniment nedorit constă în îndepărtarea cât mai rapidă a implantului. Tratamentul sinuzitei declanşate de migrarea implantului dentar în sinus presupune o dublă abordare, medicamentoasă şi chirurgicală, care să asigure drenajul şi ventilația sinuzală. Se începe un tratament medicamentos cu 1 g amoxicilină/de 2 ori pe zi, timp de o săptămână. Prima doză de antibiotic se aministrează cu o oră înaintea intervenției chirurgicale (10). 
Tratamentul chirurgical poate îmbrăca una dintre căile de acces deja descrise în funcție de particularitățile cazului clinic. Căile de abordare pot fi diverse: prin neoalveolă, endoscopie transnazală $(11,12)$ sau tehnica clasică chirurgicală CaldwellLuc (13).

Îndepărtarea implanturilor dentare migrate în sinusul maxilar se poate face, după unele opinii, fie printr-o abordare chirurgicală intraorală, fie printro tehnică chirurgicală de endoscopie sinuzală funcțională sau chiar prin combinarea acestora. Intervenția convențională Caldwell-Luc, cu antrostomia meatului inferior, nu este o opțiune recomandabilă, deoarece nu reuşeşte obținerea unei ventilații normale a sinusului maxilar (7).

Abordarea chirurgicală intraorală presupune crearea unei ferestre osoase în peretele antero-lateral al sinusului maxilar, după prealabila decolare a unui lambou mucoperiostal, oferind şi posibilitatea închiderii unei eventuale comunicări buco-sinuzale preexistente printr-un lambou vestibular sau palatinal (7).

Endoscopia sinuzală funcțională este o manevră mult mai puțin invazivă, constând în uncinectomie parțială, antrostomia meatului mijlociu şi lărgirea ostiumului meatal executate sub anestezie generală, ceea ce permire tratamentul eficient al unei sinuzite asociate deplasării implantului în sinus şi repermeabilizarea ostiumului blocat de inflamația mucoasei. În caz de inflamație pansinuzală, permite şi accesarea sinusurilor etmoidale, sfenoidale sau a recesului sinusului frontal (7).

Avantajele endoscopiei sinuzale funcţionale constau în caracterul miniinvaziv, posibilitatea de inspecție şi tratament controlat al mucoasei nazale şi sinusurilor maxilar, frontal, sfenoidal sau al celulelor etmoidale, precum şi efectuarea toaletei ostiumului. Ca dezavantaj trebuie amintită formarea de sinechii, cicatrice întinse între conca inferioară şi septul nazal, care nu afectează insă ventilaţia normală (7).

În acest context, folosirea exclusivă a abordării chirurgicale intraorale se recomandă pentru îndepărtarea implanturilor când nu există semne clinice de sinuzită şi ostiumul este permeabil, indiferent de asocierea sau nu a unei comunicări buco-sinuzale. În cazul existenței unei comunicări, implantul se extrage pe această cale preexistentă, iar în lipsa comunicării, prin crearea unei ferestre osoase în pere- tele antero-lateral al sinusului, dar la care nu se practică şi antrostomia în meatul inferior (7).

Asocierea abordării chirurgicale intraorale cu endoscopia sinuzală funcțională este indicată în caz de sinuzită, ostium impermeabil şi comunicare buco-sinuzală (7).

Complicațiile infecțioase cronice adiacente migrării unor implanturi dentare în sinusurile maxilare, printre care uneori se numără şi aspergiloza (14), provoacă resorbția pereților osoşi ai cavităţii sinuzale şi un efect de succiune prin modificarea presiunii naso-sinuzale (5).

Clinic, aspergiloza sinuzală se poate manifesta prin forme superficiale, reacții alergice, micotoxicoză, sau forme invazive care penetrează țesuturile subiacente amenințând existența. În timp ce formele superficiale pot interesa uneori şi indivizi imunocompetenți, la care reprezintă infecții oportuniste, celelalte forme clinice afectează practic doar indivizii imunocompromişi (14-17).

Ciupercile genului Aspergillus nu pot penetra activ tegumentele şi mucoasele intacte anatomic, deoarece nu au proprietăți keratolitice, dar le pot străbate în cazul leziunilor preexistente sau al scăderii de natură sistemică a capacității de apărare tisulară locală $(18,19)$.

Organismul uman deține mai multe linii de apărare împotriva sporilor de Aspergillus. Un prim mecanism constă în îndepărtarea mecanică prin mişcarea cililor mucoasei respiratorii. Un al doilea mecanism este reprezentat de distrugerea intracelulară în macrofagele alveolelor pulmonare şi în pneumocitele de tip II (20).

De reținut şi alternativa defensivă a polimorfonclearelor neutrofile care sechestrează intracelular prin mecanism nefagocitar atât conidiile, cât şi hifele (21), precum şi intervenția peptidelor antimicrobiene sintetizate de mucoasa respiratorie (22).

Cea mai gravă formă clinică, aspergiloza sinuzală invazivă, care are ca principal agent cauzal ciupercile genului Aspergillus (8), este favorizată de slăbirea apărării imune în alcoolism cronic, malnutiție, ciroză hepatică, diabet zaharat, traumatisme, arsuri, administrarea incorectă a antibioticelor, neoplasme, radioterapia, tratamentele cu imunosupresoare din transplantele medulare sau de organe, chimioterapia oncologică, administarea prelungită de corticosteroizi, neutropenii, leucemia acută, SIDA, afecțiunile pulmonare cronice sau stadiile finale de insuficiență renală (21-23). 
Un factor de risc potențial îl pot constitui şi tratamentele sistemice cu agenți anti-TNF $\alpha$ în artrite reumatoide şi psoriazice, psoriazis, colita ulcerativă, boala Crohn etc. Ca urmare a inhibării recrutării neutrofilelor şi potențialului antifungic al neutrofilelor şi macrofagelor prin blocarea activității citokinei proinflamatorii $\mathrm{TNF} \alpha$, se poate favoriza atât dezvoltarea unor infecții preexistente latente (tuberculoza), cât şi a unora oportuniste, precum aspergiloza, histoplasmoza, legioneloza, pneumocistoza şi listerioza (24).

Important de reținut este că atât evoluția, cât şi tratamentul aspergilozei sinusurilor maxilare depinde nu într-atât de numărul şi virulența sporilor de Aspergillus inhalați, cât de potențialul defensiv imun al organismului-gazdă, mult compromis în special în cancer, leucemii, transplante de organ etc. (17).

În acest context, la persoanele imunocompetente se consideră că tratamentul unei aspergiloze neinvazive a sinusului maxilar trebuie țintit doar pe exereza chirurgicală a masei tisulare infectate, fără o terapie sistemică antimicotică, exceptând cazurile de persistență postoperatorie mai îndelungată a radioopacității sinuzale sau ale unei simptomatologii clinice care nu confirmă vindecarea (6).

În schimb, la persoanele imunocompromise, afectate îndeosebi de forma clinică de aspergiloză invazivă, managementul infecției micotice trebuie în mod obligatoriu să urmărească efectuarea unei intervenții chirurgicale prompte şi extinse, asociată cu terapia antifungică generală de lungă durată (6).

În forma alergică de aspergiloză sinuzală, asociată cu polipi nazali şi eozinofilie locală, de regulă se recomandă excizia polipului şi repermeabilizarea ostiumului meatal obstruat (6).

Cea mai bună opțiune clinică preventivă pentru evitarea migrării unui implant dentar în sinusul maxilar după inserarea în os şi generarea unei sinuzite cronice de natură micotică constă în îndepărtarea sa imediată în caz de eşec al osteointegrării.

\section{MENTIUUNE}

Toți autorii au contribuție egală în realizarea articolului.

Conflict of interest: none declared

Financial support: none declared

\section{BIBLIOGRAFIE}

1. Leonhardt A., Grondahl K., Bergstrom C., Lekholm U. Long-term follow-up of osseointegrated titanium implants using clinical, radiographic and microbiological parameters. Clin Oral Implants Res 2002; 13(2):127-132.

2. Sgaramella N., Tartaro G., D'Amato S., Santagata M., Colella G. Displacement of dental implants into the maxillary sinus: a retrospective study of twenty-one patients. Clin Implant Dent Relat Res 2016; 18(1):62-72.

3. Guler N., Delilbasi C. Ectopic dental implants in the maxillary sinus. Quintessence Int 2007; 38(3):238-239.

4. Galindo P., Sanchez-Fernandez E., Avila G., Cutando A., Fernandez J.E. Migration of implants into the maxillary sinus: two clinical cases. Int J Oral Maxillofac Implants 2005; 20(2):291-295.

5. Scarano A., Perrotti V., Carinci F., Shibli J.A. Removal of a migrated dental implant from the maxillary sinus after 7 years:a case report. Oral Maxillofac Surg 2011; 15(4):239243.

6. Sohn D.S., Lee J.K., Shin H.I., Choi B.J., An K.M. Fungal infection as a complication of sinus bone grafting and implants: a case reports. Oral Surg Oral Med Oral Pathol Oral Radiol Endod 2009; 107(3):375-380.

7. Chiapasco M., Felisati G., Maccari A., Borloni R., Gatti F., Di Leo F. The management of complications following displacement of oral implants in the paranasal sinuses: a multicenter clinical report and proposed treatment protocols. Int J Oral Maxillofac Surg 2009; 38(1):1273-1278.

8. Haben C.M., Balys R., Frenkiel S. Dental implant migration into the ethmoid sinus. J Otolaryngol 2003; 32(5):342-344.

9. Felisati G., Lozza P., Chiapasco M., Borloni R. Endoscopic removal of an unusual foreign body in the sphenoid sinus: an oral implant. Clin Oral Implants Res 2007; 18(6):776-780.

10. Scarano A., Piattelli M., Carinci F., Perrotti V. Removal, after 7 years, of an implant displaced into the maxillary sinus. A clinical and histologic case report. J Osseointegr 2009; 1(1):35-40.

11. Kim J.W., Lee C.H., Kwon T.K., Kim D.K. Endoscopic removal of a dental implant through a middle meatal antrostomy. Br J Oral Maxillofac Surg 2007; 45(5):408-409.

12. Kitamura A. Removal of a migrated dental implant from the maxillary sinus by transnazal endoscopy. Br J Oral Maxillofac Surg 2007; 45(5):410-411.

13. lida S., Tanaka N., Kogo M., Matsuya T. Migration of a dental implant into the maxillary sinus: a case report. Int J Oral Maxillofac Surg 2000; 29(5):358-359.

14. Harada T., Isomura E.T., Uchihashi T., Kogo M. Aspergillosis associated with migration of a dental implant into the maxillary sinus: a case report. J Oral Maxillofac Surg Med Pathol 2017; 29(5):448-451.

15. Khongkhunthian P., Reichart P.A. Aspergillosis of the maxillary sinus as a complication of overfilling root canal material into the sinus: report of two cases. J Endod 2001; 27(7):476-478.

16. Giardino L., Pontieri F., Savoldi E., Tallarigo F. Aspergillus mycetoma of the maxillary sinus secondary to overfilling of a root canal. J Endod 2006; 32(7):692-694.

17. Kiriyama T., Murayama S.Y., Myoken Y. Confirmatory diagnosis of invasive maxillary sinus aspergillosis by in situ 
hybridization: report of two cases in immunocompetent subjects. J Oral Maxillofac Surg Med Pathol 2012; 24(2):124-127.

18. Agarwal M.K., Shukla P.K. Aspergillosis of the maxillary sinus. IJO \& HNS 1998; 50(1):43-45.

19. Urs A.B., Singh H., Nunia K., Mohanty S., Gupta S. Post endodontic aspergillosis in an immunocompetent individual. J Clin Exp Dent 2015; 784):e535-539.

20. Mohindra S., Mehta R., Bal A. ABPA concomitantly occuring with invasive sinus aspergillosis: a short report on two patients. Indian J Otolaryngol Head Neck Surg 2014; 66(Suppl 1):S329-S333.

21. Hohl T.M., Feldmesser M. Aspergillus fumigatus: principles of pathogenesis and host defense. Eukaryot Cell 2007; 6(11):1953-1963.
22. Ben-Ami R., Lewis R.E., Kontoyiannis D.P. Enemy of the (immunosuppressed) state: an update on the pathogenesis of Aspergillus fumigatus infection. Br J Haematol 2010; 150(4):406-417.

23. Peral-Cagigal B., Redondo-Gonzalez L.M., VerrierHernandez A. Invasive maxillary sinus aspergillosis: a case report succesfully treated with voriconazole and surgical debridement. J Clin Exp Dent 2014; 6(4):e448-451.

24. Guivarc'h M., Ordioni U., Catherine J.H., Campana F., Camps J., Bukiet F. Implications of endodontic-related sinus aspergillosis in a patient treated by infliximab: a case report. J Endod 2015; 41(1):125-129. 